\title{
Atrioventricular conduction disturbance as an early feature of Reiter's syndrome
}

\author{
J F HAVERMAN, ${ }^{1}$ G A VAN ALBADA-KUIPERS, ${ }^{3}$ H J M DOHMEN, ${ }^{2}$ \\ AND B A C DIJKMANS
}

From the Departments of ${ }^{1}$ Rheumatology and ${ }^{2}$ Cardiology of the Groot Ziekengasthuis, 's Hertogenbosch, and the ${ }^{3}$ Department of Rheumatology, University Hospital, Leiden, The Netherlands

SUMMARY Atrioventricular (A-V) conduction disturbances in Reiter's syndrome are usually described in longstanding disease. This report deals with two male patients with Reiter's syndrome who developed an A-V block early in the course of the disease. One of these patients developed a second degree A-V block, Wenckebach type, which has not been described before at an early stage of this syndrome.

Key word: heart block.

Cardiac manifestations such as conduction disturbances and aortic regurgitation have long been recognised as part of the syndrome in patients with ankylosing spondylitis, ${ }^{12}$ and also in Reiter's syndrome. $^{3-9}$ In spondylitic disease two clinical forms of heart disease may occur, one being aortitis $^{10} 11$ and the other atrioventricular (A-V) conduction abnormalities. ${ }^{1} 1112$ In Reiter's syndrome conduction abnormalities have been described in most cases late in the disease. ${ }^{3-9}$ In the first weeks of Reiter's syndrome A-V conduction abnormalities are infrequent. ${ }^{69}$

We report two patients with Reiter's syndrome who developed A-V block early in the course of the disease.

\section{Case reports}

PATIENT 1

A 40 year old man developed urethritis in May 1985. He had previously felt healthy but since 1973 had been known to suffer from essential hypertension, for which he was treated with chlorothiazide, hydralazine, and metoprolol.

The medical history and physical examination in May 1985 disclosed no further abnormalities; cultures of the urethral fluid showed Chlamydia trachomatis. After treatment with tetracycline for three

Accepted for publication 25 April 1988.

Correspondence to Dr B A C Dijkmans, Department of Rheumatology, Building 1, C2-Q, University Hospital, PO Box 9600, 2300 RC Leiden, The Netherlands. weeks the urethritis disappeared. In mid-June the left second, third, and fourth metatarsophalangeal joints were tender and swollen, and the right knee and shoulder became painful without swelling. Two weeks later the patient felt a thumping sensation in his chest and experienced attacks of tachycardia and bradycardia. When seen in July he appeared healthy, height $180 \mathrm{~cm}$ and weight $76 \mathrm{~kg}$. The pulse rate was $120 / \mathrm{min}$ and regular, the blood pressure $170 / 90 \mathrm{mmHg}$. Examination showed no skin abnormalities or lymphadenopathy. The heart and lungs were normal, the liver not enlarged, and the spleen was not palpable. There were no ophthalmological abnormalities. The swollen left metatarsophalangeal joints were tender. Examination of the spine disclosed no abnormalities.

The erythrocyte sedimentation rate was $29 \mathrm{~mm}$ (Westergren) in the first hour, haemoglobin was 142 $\mathrm{g} / \mathrm{l}$, and the white blood cell count was $7 \cdot 2 \times 10^{9} / 1$ with normal differential. The Waaler-Rose and latex fixation tests were negative. Antinuclear factors were present, Liver, kidney, and thyroid function tests were normal, as was the serum urate concentration. The results of urine analysis were normal. The HLA-B27 antigen was present. Radiographs of the chest, feet, and pelvis were normal.

A resting cardiogram after stopping beta blockade showed a sinus rhythm at a rate of $75 / \mathrm{min}$, and a second-degree A-V block, Wenckebach type (Fig. 1). Earlier electrocardiograms (ECGs) were normal. Exercise at 200 watt was performed without precordial pain; the fastest heart rate was $148 / \mathrm{min}$; 


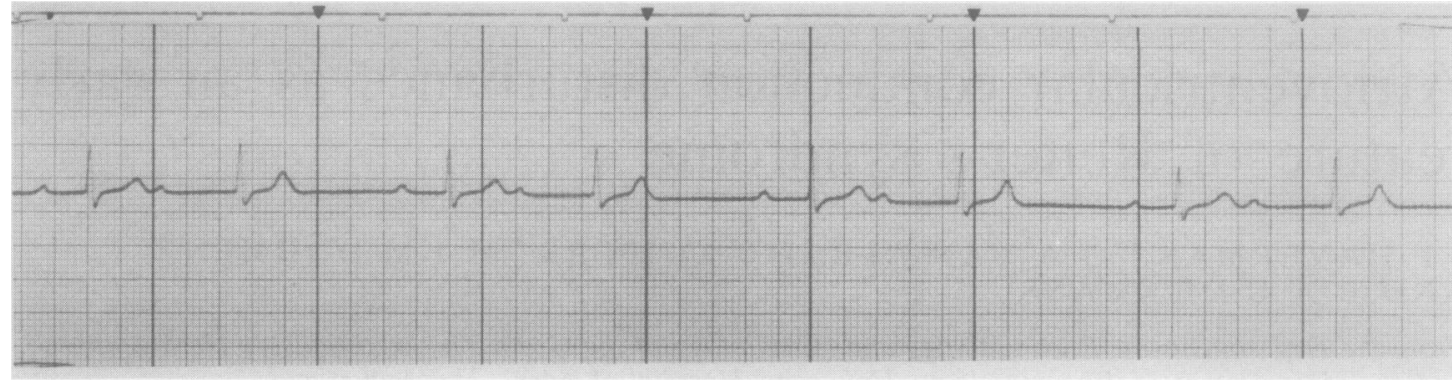

Fig. 1 Second degree A-V block, type Wenckebach, in patient 1 .

just before the end of the exercise the second degree A-V block converted to first degree. After exercise the first degree A-V block reverted to second degree.

A 24 hour electrocardiographic recording showed an almost continuous second degree $\mathrm{A}-\mathrm{V}$ block of the Wenckebach type; the slowest heart rate was 40 beats/min the highest 128 . Electrophysiological studies disclosed an $\mathrm{H}-\mathrm{V}$ time of $50 \mathrm{~ms}$. Stimulation of the right atrium at an atrial frequency of 150 continuously showed a second degree A-V block, maximum 4:1. After stimulation the second degree Wenckebach-type A-V block reappeared.

Echocardiography disclosed no abnormalities. Angiography of the coronary arteries, especially the A-V node artery, gave normal results. On the basis of the above findings a diagnosis of Reiter's syndrome following chlamydial urethritis was made; the A-V conduction disturbance was considered to be part of the syndrome. The administration of hydralazine was discontinued in July 1985 . The antinuclear factor became negative. The palpitations and the pain in the forefoot did not diminish.

\section{PATIENT 2}

A 49 year old previously healthy man developed diarrhoea in June 1986 after travelling in Turkey. One week later he developed conjunctivitis and urethritis and after another week his left knee and ankle became tender and painful.

On examination he appeared healthy with a pulse rate of $100 / \mathrm{min}$, which was regular, and a blood pressure of $150 / 90 \mathrm{mmHg}$. His temperature was $38^{\circ} \mathrm{C}$. Both eyes showed iridocyclitis. The heart and lungs appeared normal. The liver was not enlarged and the spleen not palpable. No skin abnormalities were present except circinate balanitis. Examination of the joints disclosed a warm and swollen left knee and ankle and tender left second and third metatarsophalangeal joints. Examination of the spine disclosed no abnormalities.
The erythrocyte sedimentation rate was $78 \mathrm{~mm}$ (Westergren) in the first hour, haemoglobin $130 \mathrm{~g} / \mathrm{l}, ?$ and the white blood cell count $9 \cdot 8 \times 10^{9} / 1$ with $\vec{\circ}$ normal differential. The Waaler-Rose and latex
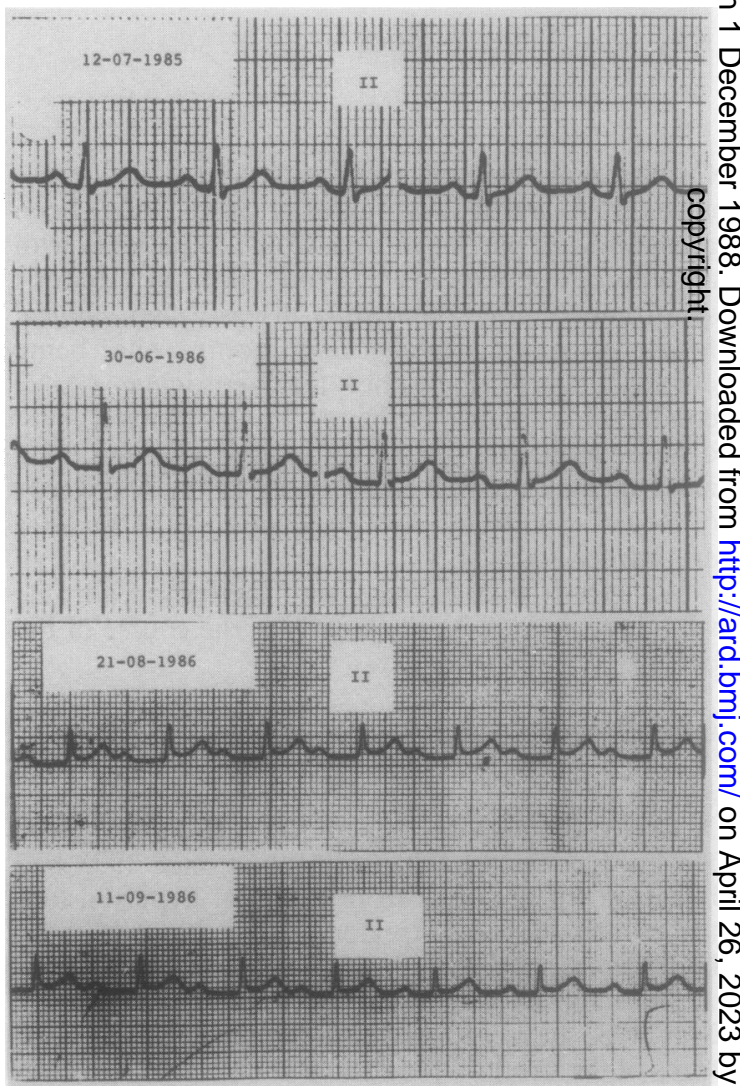

Fig. 2 Electrocardiograms (ECGs) of patient 2. The ECG of 1985 was made before Reiter's syndrome developed and shows a normal P-R interval. The ECGs of 1986, which were made during the course of Reiter's syndrome, show a prolonged $P-R$ interval. 
fixation tests gave negative results, and antinuclear antibodies were absent. Kidney function tests were normal. The alkaline phosphatase and serum alanine transaminase levels were raised at $111 \mathrm{U} / \mathrm{l}$ (normal 60) and $31 \mathrm{U} / \mathrm{l}$ (normal 15) respectively. Serum aspartate transaminase and lactic dehydrogenase concentrations were normal. HLA-B27 antigen was present. The results of urine analysis were normal. Radiographs of the chest, pelvis, knees, ankles, and feet were normal. Faeces were not cultured. Serological tests for hepatitis A and B gave negative results.

A resting electrocardiogram, recorded at the end of June 1986, showed a sinus rhythm at a rate of $84 / \mathrm{min}$, a first degree A-V block (P-R interval $0.22 \mathrm{~s}$ ), and an incomplete right bundle branch block. A resting electrocardiogram two months later showed a more pronounced A-V block (P-R interval $0.30 \mathrm{~s})$. A cardiogram recorded in 1985 showed a $\mathrm{P}-\mathrm{R}$ interval of $0.16 \mathrm{~s}$ (Fig. 2).

Echocardiography and phonocardiography gave normal results. On the basis of these findings a diagnosis was made of Reiter's syndrome probably triggered by an enteric infection; the $\mathrm{A}-\mathrm{V}$ conduction disturbance was considered part of the syndrome. Treatment consisted of advice about daily living and treatment with non-steroidal anti-inflammatory drugs. The arthritis gradually disappeared, but the patient continued to experience recurrent balanitis and iridocyclitis. An ECG recorded in September 1986 showed a P-R interval of $0 \cdot 24 \mathrm{~s}$.

\section{Discussion}

These case histories highlight the occurrence of A-V conduction disturbances early in the course of Reiter's syndrome. The finding of early cardiac abnormalities confirms that conduction delay may be an early manifestation of the disease. ${ }^{3-6}$ In an earlier review of published work Csonka et al reported ECG abnormalities in a 'fairly high proportion' of cases. ${ }^{6}$ The most constant finding was a prolonged P-R interval. ${ }^{6}$ In most cases the changes were noted in the first weeks after the onset of the disease; however, some of the described patients had had several attacks of Reiter's syndrome before cardiac abnormalities developed. ${ }^{6}$ Our first patient showed a second degree A-V block, which has not previously been described early in the course of Reiter's syndrome. Cardiological investigation, including angiography, was performed during the first few weeks after the onset of Reiter's syndrome and did not disclose any anatomical abnormalities. When this type of conduction disorder develops the localisation is usually in the A-V node. ${ }^{8}$ If it is assumed that no major morphological cardiac abnormalities are responsible for the conduction disturbance then its pathogenesis is a matter for speculation. In ankylosing spondylitis the morphological changes consist of a chronic inflammatory infiltrate in the membranous portion of the interventricular septum, fibrosis, and neovascularisation, sometimes accompanied by calcification, ossification, and chondrification, the sequence being similar to that of the inflammatory process occurring in the joints in this disease. ${ }^{12}$ In the seronegative spondyloarthropathies inflammation affects entheses, whose chemical composition closely resembles that of the hard connective tissues in which 3hydroxypyridinium forms part of the principal collagen cross link. This substance is also a critical constituent of collagen in the aortic root, which is situated near the A-V node. This type of collagenous tissue may be selectively susceptible to inflammation. ${ }^{13}$ Furthermore, it is also uncertain whether a circulating antigen derived from Chlamydia trachomatis or from an enteric organism has local effects that induce the conduction disturbance.

Another factor involved in the genesis of conduction disturbances may be the presence of the HLA antigen. This hypothesis is supported by the finding that the prevalence of B27 is significantly higher in patients with complete heart block and pacemaker treatment in the absence of clinical or radiological evidence of a seronegative spondyloarthropathy. ${ }^{14}$ The incidence of cardiac involvement in patients with Reiter's syndrome has been reported to amount to $10 \%$ in both the presence and absence of the HLA antigen B27, ${ }^{15}$ which indicates that the presence of this antigen is not obligatory for the development of a conduction abnormality. Treatment for the A-V block is still a controversial question. It has been suggested that treatment with atropine is effective and that an artificial pacemaker is not always indicated. ${ }^{8}$

In practice, the cardiologist who is confronted with $\mathrm{A}-\mathrm{V}$ conduction disturbance must be aware that this abnormality can be part of seronegative spondyloarthropathy and the rheumatologist treating a patient with a seronegative spondyloarthropathy should be aware of the possibility of the development of conduction abnormalities.

\footnotetext{
References

1 Bernstein L, Brock O J. Cardiac complications in spondylarthritis ankylopoietica. Acta Med Scand 1949; 135: 185-94.

2 Cats A, Goslings J. Aorta-insufficiëntie bij spondylitis ankylopoietica. Ned Tijdschr Geneeskd 1961; 105: 1242-6.

3 Feiring W. Reiter's disease with prolonged auriculoventricular conduction. Ann Intern Med 1946; 25: 498-507.

4 Paronen I. Reiter's disease: a study of 344 cases observed in Finland. Acta Rheumatologica Scandinavica 1948; (suppl 212); 1-114.
} 
5 Neu L T, Reider R A, Mack R E. Cardiac involvement in Reiter's disease: report of a case with review of the literature. Ann Intern Med 1960; 53: 215-20.

6 Csonka C W, Litchfield J W, Oates J K, Willcox R R. Cardiac lesions in Reiter's disease. Br Med J 1961; i: 243-7.

7 Cliff J M. Spinal bony bridging and carditis in Reiter's disease. Ann Rheum Dis 1971; 30: 171-9.

8 Rossen R M, Goodman D J, Harrison D C. A-V conduction disturbances in Reiter's syndrome. Am J Med 1975; 58: 280-4.

9 Good A E. Reiter's disease: a review with special attention to cardiovascular and neurologic sequellae. Semin Arthritis Rheum 1974; 3: 253-86.

10 LaBresh K, Lally E V, Sharma S C, Ho G. Two-dimensional echographic detection of preclinical aortic root abnormalities in rheumatoid variant diseases. Am J Med 1985; 78: 908-12.
11 Qaiyumi S, Hassan Z U, Toone E. Seronegative spondylarthropathies in lone aortic insufficiency. Arch Intern Med 1985; 145: 822-4.

12 Alexander B, Feiner $H$. Ankylosing spondylitis with cardiac $\overrightarrow{\widehat{N}}$ dysrhythmia. Pathologic changes in cardiac conduction system. NY State J Med 1979; 79: 1585-8.

13 Jacobs J C. Spondylarthritis and enthesopathy. Arch Intern Med 1983; 143: 103-7.

14 Bergfeldt L, Möller E. Complete heart block-another HLA B27 associated disease manifestation. Tissue Antigens 1983; 21: 385-90.

15 Leirisalo M, Skylv G, Kousa M, et al. Follow-up study on patients with Reiter's disease and reactive arthritis, with special reference to HLA B27. Arthritis Rheum 1982; 25: 249-59. 